\title{
Urgences
}

\section{J'ai enfin osé...}

\section{Danielle Bérubé}

Numéro 10, 2e trimestre 1984

\section{Spécial fantasmes}

URI : https://id.erudit.org/iderudit/025149ar

DOI : https://doi.org/10.7202/025149ar

Aller au sommaire du numéro

\section{Éditeur(s)}

Urgences

\section{ISSN}

0226-9554 (imprimé)

1927-3924 (numérique)

Découvrir la revue

Citer ce document

Bérubé, D. (1984). J'ai enfin osé... Urgences, (10), 5-6.

https://doi.org/10.7202/025149ar d'utilisation que vous pouvez consulter en ligne.

https://apropos.erudit.org/fr/usagers/politique-dutilisation/ 


\section{J'AI ENFIN OSÉ...}

J'ai posé ma main sur sa peau blanche et les émotions me sont montées à la gorge...

Tout en essayant de placer mes "hallucinettes", je me suis rendu compte, qu'au fil du temps, les sensations se faisaient plus nombreuses et plus pressantes... II y avait toujours cette lettre, sur le coin du bureau, qui attendait son facteur!... elle attendrait encore!...

Moi, je me laissais prendre au jeu des images et des mots... Je fantasmais de plaisir à voir cette dixième étape arrivée bientôt sur les rangs...

Je me posais aussi quelques questions: entre dehors et dedans, que choisir?... que faire quand le temps serait venu de tout leur dire... de sortir de cette solitude à ne plus savoir comment partir du bon pied?...

Au milieu de son corps, il y avait comme un potager où poussait "le navet bleu" des enfants "Oedipe"... semblable aussi à ce cimetière là-bas à New-Carlisle... ma main pouvait y aller ou revenir à sa guise...

$J$ 'ai mis la main sur ces textes du numéro 10 de la revue URGENCES avec un peu de retenue, comme si les mots pouvaient mordre ou griffer...

J'ai, avec Jean-Pierre April, ajusté mes "hallucinettes" une fois pour toutes, pour mieux voir les fantasmes couchés sur le papier: cette peau blanche,... pour mieux comprendre Madeleine Gagnon et sa solitude "fantasmique"... pour saisir au vol, "(by) Air Mail" les petits mots de Marie Bélisle... pour connaître le potager de Jean-Marc Cormier et les "femmetasmes" de Jean Cossette... pour retrou- 
ver la marée montante du cimetière d'une "nuit de New-Carlisle" de Gilbert Dupuis...

Je me suis laissée envahir par les images et les mots en situant cette "Simple marche" de Marcel Boucher sur mon échiquier quotidien tout en ayant des performances à accomplir avec Vianney Gallant pour que les fantasmes d'URGENCES 10 demeurent vivants... pour en savoir plus sur l'ombre de son âme avec Mario Joubert... pour avoir beaucoup moins peur de m'éveiller avec les mots de Mario Canuel...

Quand enfin, pour vraiment "Fantasmé" avec Renald Bérubé, je dois cesser de répéter " $F$ pour... $F^{\prime \prime}$ avec Suzanne Lavoie et vous avoir tout dit du contenu du numéro 10 de la revue URGENCES: le numéro spécial "FANTASMES"...

$\mathrm{N}^{\prime}$ ayez pas la même crainte que moi... prenez la revue à pleine main... N'hésitez plus, elle ne mord ni ne griffe, je le sais maintenant... Maintenant que les parutions commentées ont suivi leurs cours et que je m'apprête à vous dire combien ces "variations" poétiques "damnées" m'ont encouragée à sortir de ma cage, vous pourrez venir me voir... je suis facilement reconnaissable: je suis la seule personne à trois yeux griffés qui, la plume à la main comme Paul-Chanel Malenfant, a inventé cette préface fantastique pour ce numéro 10 ... Bons fantasmes... à réaliser...

\section{Danielle Bérubé}

pour le Comité de direction 